\title{
Legal Support of Planning in the PRC
}

\author{
Olga Kucher \\ Institute of Economics and Legal Research of the National Academy of Sciences of Ukraine, \\ Donetsk, Ukraine \\ Email: osk.mermaid@gmail.com
}

Received February $25^{\text {th }}, 2013$; revised March 28 $8^{\text {th }}, 2013$; accepted April $5^{\text {th }}, 2013$

\begin{abstract}
Copyright (C) 2013 Olga Kucher. This is an open access article distributed under the Creative Commons Attribution License, which permits unrestricted use, distribution, and reproduction in any medium, provided the original work is properly cited.
\end{abstract}

\begin{abstract}
Looking at the People's Republic of China (PRC) reforms it is necessary to mention that they were not resulted from foreign experts or from other countries experience they were a result of a long term Chinese strategy. This strategy includes such aspects as economy system, social benefits national safety provided that PRC is open to international influence. This long term strategy has its main tools of planning system. With the help of such system government can control all market processes which, for sure, lead to the growth and success in economy. Alongside of such model, Chinese government before and nowadays use methods of direct and indirect regulations as well as administrative influence. It means that such government interference in market process will make state structures powerful and experienced players in this game. It is necessary to say that in the period of globalized world economy multinational corporations started influencing all processes more and more, and we need to review role of government regulation. In this work next step will be directed at legal support and identification of effective government functions which can influence and control private sector. These government functions regulation can help to create balance between state, private assets and international organization in order to have a good basis for competitive world economic position. The article has a purpose to analyze key features of Chinese planning system, distinguish peculiarities and apply to other systems. In the article following methods are used chronological development of the system starting from the beginning; dialectical method of making conclusion basing on facts; and elements of comparative analysis. Result of this article is opportunity to apply such characteristics to other countries.
\end{abstract}

Keywords: Planning System Genesis; Asian Planning System; Legal Mechanism; Legal Support

\section{Introduction}

Nowadays world known scientists are divided into two opposite groups because of their opinions. The first group is certain that society need to have more liberalized economies which can provide more development. The second one thinks that planning economy is one of the most disciplined and stimulative for stable economic growth. Those who are against planning system give a lot of arguments and justify their opinions by the fact that market system and planning system can not coexist, because they are mutually exclusive. The second group supposes that it is possible to integrate these two systems.

Both groups of scientists can be backed up with the recent historical precedents where it is possible to find economic reforms which we are going to research and consider and which we are going to base on.

Firstly, so-called "shock therapy", which comprises several stages such as transference of governmental assets into private ones. This way includes economic reforms on inside as well as outside liberalization process and enterprises formation and their maintenance. To sum up, it is a fast track from governmental to private sector (Selishchev, 2004). Such scenario of reforms is a typical feature of number of countries such as Ukraine, Russia, Poland.

Secondly, so called "a gradual reforming system" which does not consider full asset transference at all but insists on only partial assets between governmental and business sector. In this scenario government influence is the strongest and it has a right to decide when and how much to transfer to a business sector. Such transference is presupposed by situational necessity inside the state (Selishchev, 2004). Such option was chosen by the PRC and it is seen that the system approved itself and can be a vivid example for other countries especially after crisis period. As a consequence, it is a base for this work.

Among scientists who consider that market needs government regulation there are leading Chinese economists and lawyers such as Zhou Xincheng, Liu Guoguang, Lee Ji Shen. They work with these questions and their views can be added to each others' ideas. The main message of this group is that market is vulnerable to continuous recessions, high inflation and unemployment. Market can not liquidate negative factors such as polarization of population incomes, unequal regional development ecological cataclysms. Market can never provide national interests and needs. Markets react only at pay ability and buying powers.

Consequently, markets without government regulations can lead to negative results and absolutely damage government and state strategy, which have happened in many countries. That is why, government interference and regulations is a necessity for any state development. 


\section{Planning System Genesis}

Being a method of government regulation planning has got a fifty year history development.

- First, discussion of this system started to be developed and implemented in 1930s in Western European countries and some developing countries such as Mexico and India. The result of this discussion was the first plan creation.

- Secondly, in 1937 in the United States of America (USA) there was a scientific article published and a new book "Theory of national economy planning" was introduced. In this stage a planning system had anti-crisis nature and all scientists were sure that markets could not exist without government regulations (Atamanchuk, 2000).

- Shortly after this, in the Union of Soviet Socialist Republics (USSR) a New Economic Policy started and this policy finally showed that market could be regulated by the government.

The difference between development of these mechanisms is that in the USSR market processes were completely abolished and planning system was introduced but in European countries where there were attempts to make markets work under government regulations and control. That is why, for them it was very interesting to watch and analyze American experience because European community believed that such combination was a right to exist. Foreign experts' interest was gradually growing and increased after the USSR published their first Fife-Year Plan and started working on their long term FifteenYear Plan, so called strategic plan (Lortikyan, 1995).

More than that, some conceptual changes of understanding classical capitalism took place. These changes were connected with "New Deal" Franklin D. Roosevelt. The Franklin D. Roosevelt course was based on principles:

- Firstly, government regulation economy with restriction in monopolistic positions;

- Secondly, state control of monopoly activities;

- Thirdly, planning system elements (Pawlowski, 1997).

The results were impressive and met expectations. That is why, the USA government decided to borrow some elements and implement them into their planning system.

At that time, the USSR planning was a powerful and centralized system with a lot of branches. This system was backed with legal documents, which detailed and described all interpretations from different angles (Shvetsov, 2009). That is why, it functioned effectively. But in 1985 because of economic crisis and irrational political decision it was destroyed. It can be explained by the Soviet Institute establishment destruction and, as a consequence, ineffective management of this system.

Meanwhile, American and European countries government using, as we mentioned earlier, elements of the USSR planning system created indicative planning which proved to be effective (Mamutov, 1982). Evaluating the USSR experience, it is possible to say that system stopped working because of irrational political steps, but not because of planning system nature (Lortikyan, 1995).

Nowadays concepts of planning are used in many countries and it does not depend on their political and economic strategy. In the world it is possible to recognize 3 types of planning model:

- Firstly, North American model (the USA, Canada);

- Secondly, European model (France, Sweden);

- Thirdly, Asian model (the PRC, Japan, South Corea).
For this research, it is interesting to focus on Asian model.

\section{Asian Planning System Characteristics}

\section{Planning System Evolution in the PRC}

Development of planning system was provoked with changes in economy. Retrieval from command-administrative system into market took place in all spheres of social and economic life. It included also changes reforming institutions such as Institute of Ownership of Government Regulation and of Legislative Bodies. These changes led to creation of new ones. So far, the PRC has been dealing with planning for more than 50 years. Planning was created in the period of planning economy and it is being created now in the period of "socialist market economy".

First planning program was introduced in 1953 and at that time the USSR experience was used as a base. The PRC annual and Fife-Year Plans were created on the basis of the USSR plans and sometimes were named as "plan of national economy" (narodnokhozyajstvenij plan) (Shi Tszichun, 2007), exactly as such plans were named in the USSR at that time.

According to Chinese leading specialists such retrieval from command administrative system into market one was carried out on the basis of "territory and sector" principle (Mikheev, 2000).

- So called "territorial principle" means that market mechanism was introduced into special economic zones and coastal areas of the PRC. After successful results this mechanism expanded into the center of the country.

- So called "sect oral principle" means that market relationships were firstly developed in such spheres as small and medium-sized enterprises (SMEs), services, export manufacturing. These sectors were chosen for such experiments because they are not essential for the state and can be experimental models.

If we analyze planning system evolution in the PRC, we need to say it completely differs from the process of indicative planning evolution in developed countries. In developed countries government regulation is a new element but necessary for market system and, as a consequence, it was imposed from outside. In comparison to developed countries, in the PRC new market elements were fixed in an existing government regulation. In this way market mechanism changed goals, methods, ways of plans implementation. So, it means that Chinese reformates did not copy European model but created their own system. This model was named as "a process of crossing the river trying to identify stones at the bottom". This is a quote of one of the most famous Chinese reformates Wang Xiaoqian (Shen, 2002).

Even, in a period of Door-Opening Policy Chinese ideologists proved themselves as tolerant, patient and alternative to foreign ideas but they saved their originality and independence. This was reflected in the philosophy of such schools as Confucianism, Taoism and Legalism. All foreign ideas had a right to exist and be used, but the main beacon was a Chinese strategy. As a result, Chinese model was created as a symbiosis of all tendencies with one and the same denomination. Such Chinese reformates basing on Confucianism principles said that it is possible to use any ideas if they do not contradict to each other and principles of humanity and if such ideas affect family and state positively (Pakhomov, 2008). These ideas worked all the 
time and they are actual nowadays.

When Chinese reformers studied and analyzed some of such new ideas they had to stick to their government authorities instructions. It was considered as a moral principle for them. The reason why we mentioned this fact is that the same principle is essential for planning system: if you plan something in economy, you have to know links between different economic spheres. Planning is a process of organization of those links. Prognoses in economy are based on such links.

Chinese economic system is a system that is able to combine different and opposite ideas which can be mutually exclusive in other contexts. This demonstrates successful combination of market principles and government regulation (Pakhomov, 2008). Chinese leaders not only examined and implemented foreign ideas but also diversified and moved them in different angles taking into account government strategy and goals.

As a result, they took the best ideas from Western market as well as they selected effective Soviet practices. Using Soviet effective practices we mean a long period of time when a New Economic Policy was created. Such practices proved themselves viable even in the period of 1979 when Western countries imposed a trade embargo on the PRC. At that time Chinese governmental bodies made a decision to implement USSR development economic model. The specific features of this model were:

- Centralized planned economy and government regulation;

- Economy growth as a main focus;

- People, raw materials, financial resources were used to realize ambitious projects (Selishchev, 2004).

The first experience in marketing reforming of Chinese economy was made in 1980 s. It was connected with agrarian sphere and private sector, development in industry. These changes influenced all aspects of strategic regulations. As a result, centralized system started being transferred into decentralized system. A lot of economic figures happened to be under control of ministries, controlling organs, government agencies with the help of economic instruments such as taxation, loans, interest free loans, government purchases. Government influence was transferred into indirect form.

The PRC did not make "a shock therapy" but used "gradual approach" to transition from the old system to a new one. It can be explained with the fact that Chinese economists used 2 criteria about how reforms can be made:

- The first criteria is that reforms need to give a real effect for absolute majority of population;

- The second criteria is that a reform implementation cost must be value for money (Pakhomov, 2008).

\section{"Gradual Approach" to Transition from the Old System to a New One}

"Gradual Approach" Comprised Different Steps.

The first stage is from 1978 to 1991. This step was devoted to the development of a tool how to combine market and planning systems with a leading government role. The first legal documents which provided the idea of planning was so called government program "a Project of Reforms of Economic Regulations". This project was implemented when Deng Xiaoping was a Chinese leader. This program declared a leading role of Chinese government and principles of planning (Li Chi Shen, 2002). In 1982 the first plan was created. Its name is "a Plan of
National Economy and Social Development". This plan focused on appealed to the world development tendencies that were based on building economy which takes into account an increase of living standards of people (Ian Yuntsyu, 2010).

The second stage is connected with a new leader appointment. His name is Zhao Ziyang and he was appointed in 1992. He took a New Course of Reforms to form a policy with the help of which he could use market elements in socialism. So the main idea of the second step was to develop driving forces or work with a help of planning. If market stimulates workforce increase, it does not conflict with principles of socialism.

At the same year, on the International Conference of the United Nations Organization (UNO) on Ecology and Development, the PRC was recognized as the first country that accepted such program with the name "The 21-st Century Program". The PRC is the first country in the world which published in 1994 a long term strategy development program (Selishchev, 2004).

In the 20th century, they came from directive to indirect planning and it is possible to name four forms of planning in the indicative planning. These four forms are based on criteria of enterprises importance for government tasks fulfillment, that is what role this or that enterprise plays in the governmental strategy.

- The First type of enterprises which produce strategically important and essential types of goods to provide government with necessary raw materials due to governmental purchase. Such enterprises deliver high gross output of industry and agriculture with the small range of products. It is almost connect with natural resources and agriculture.

- The Second type of enterprises is those which change their production line due to the market processes and in accordance with the state plan. The first type makes gross margin for the state, but the second one introduces major part of SMEs but without big margin.

- The Third type of enterprises includes production of goods which are regulated by the state plan mostly and in minor part by economic supply and demand.

The Fourth type includes enterprises which are mostly regulated by market processes and only a small part is regulated by the government.

The third stage of development strategy in Chinese planning was in the 21-st century. The goal of this stage was to increase level of economy to high standards in developed countries. This stage brought in the PRC from administrative to planning economy system. This stage was based on ideas developed by Deng Xiaoping. These ideas are popular now. He said that the PRC built "socialism with Chinese specific features" (Sukharev, 2001). It is not only theory. It is a mechanism which can work in practice. This mechanism can be defined as a program with a long term strategic plan.

One of the reasons of high economy level in the PRC is the fact that Chinese reformers while reforming something assessed results of success or failures with special criteria. This helps to develop production and improve living standards. For Chinese reformers, development was a goal, stability was a prerequisite and reforming is a driving force.

"Socialism with Chinese specific features" means market with socialistic economy and this term is an official one which we see in Chinese Constitution. As Institution, we understand socialism as a variety of business forms with state power dominance above collective property. This mechanism is based on market self-regulation with powerful macro-economic state 
influence.

\section{Five Directions of Changes in Planning System}

During three chronological stages of development it is possible to point out 5 directions of changes in planning system (Kuzyk, 2008). These directions were reflected in "the Reform and Opening Up" concept.

- First direction was spotted before 1980s (so called the sixth Five-Year Plan). The idea of this direction was a quantified assessment of agriculture and industry. Social sphere left behind this figures. Later, these figures would become figures of economic and social development and also it included environment and protection of natural resources.

- Second direction started in 1990 (it was the eighth FiveYear Plan). It was the first time when they started to create long term plans for 10 years. Consequently, in 1996 when the ninth Five-Year Plan started, Chinese reformates prepared long term 15 year plan.

- The third direction was focused on transition from command into market economy. Directives power decreased and indicative planning power grew. Figures of planning changed their function and they started predicting more than indicating.

- The fourth direction was connected with the growth of regional planning. At that time government planning had a predictable character and regional figures showed real situation.

- The fifth direction was connected more with high technologies and information resources. Nowadays, business environment has more power for corrective actions. This direction helped enterprises meet expectations and reach planned figures using more technologies and information resources which make them more flexible and advanced (Kuzyk, 2008).

As a conclusion, Chinese planning system had a complicated vertical and horizontal development in terms of state and business relationship as well as interaction of different spheres. In this development Chinese reformates reached the first goal to regulate economy structure and illuminate disproportion. More than that, they managed to have multisided strategic regulation.

\section{Modern Legal Mechanism of Planning in the PRC}

\section{Plans by Spheres}

Nowadays the PRC has multilevel system of legal regulation. They use 2 methods: direct and indirect. Usage of these methods depends on different business forms which define ownership of such enterprises. Though, Chinese main approach to planning is a complex balancing. All businesses are considered in government planning and they have to drive this plan. The reason for this is that government can control development of these businesses (Tymoshchuk, 2005). That is why, we can say about 3 types of planning: planning by programs, planning by objects, regional planning and planning of branches.

- Planning by programs means that it is necessary to develop programs for economy development. Such programs play the main and driving role among others. It concentrates on macro-economic policies.

- Planning by objects is mostly controlled by government goals and aims and considered as a means of primary func- tions. For example, this type of planning was used in building railway in Tibet or hydro-electro station on the Yangtze River. This type of planning is rooted from planning by programs. It helps to locate these objects on the territory to distribute natural resources effectively.

- Regional planning and planning of branches. Regional planning is a plan created by regional government and authorities. It is a level of provinces. These plans must be in compliance with planning by programs. Regional planning is concentrated on the situation in the region. Planning of branches takes into account some tendencies in different industries. It is closely connected with technological and business specific features also it considers inter-industrial integration. These plans help to analyze tendencies of the market development inside the country. These plans make the country be competitive on international level (Kuzyk, 2008).

\section{Plans by Terms}

All plans such as by programs, objects, regions and branches can be divided into long term (10 - 20 years plans), middle term ( 5 years plans) and short term ( $1-3$ years plans).

- Long term plans are based on planning by programs. They focus on economy, science, new technologies and innovations in social spheres. Such plans do not include details but they concentrate on economic growth, main objects of the economy, economy policy and main measurement with the help of which it is possible to implement such strategic plans. Such long term plans play the main role in the planning system.

Chinese specialists explain this fact with 3 reasons:

1) When we create long term plan it helps to use scientific technologies at full capacity including scientific prognosis as well. In such long term plans it is possible to take into account real prognosis. It is more accurate to assess economy in such prognosis and make rational and correct conclusion;

2) Such long term plans can improve industrial development and technological structure;

3) Long term plans have several functions such as mobilization, stabilization and stimulation of inhabitants activities (Kuzyk, 2008).

- Middle term plan is a bridge between long term and short term plans. This kind of planning is focused on details:

1) Economic growth pace;

2) Main assets for natural economy development;

3) Spheres and impacts of capital investments;

4) Problems which are connected with development and implementation of science and technological progress results;

5) Living standards of rural and village settlements;

6) Usage of natural and environmental resources in effective way under government control;

7) Birthrate and natural demographic growth;

8) Measures to implement strategic plan (Popova, 2008).

Short term planning considers and includes aspects of middle term plans. Results of short term plans are combined in long term plans. As an example we can analyze situation in 2000 when Chinese government in their long term plan set a goal to improve industrial development. That is why, in the middle term plan they decided in which region it could be more effective taking into account laws about natural resources, birthrate, labor force in different regions. Consequently, in the short term 
plan they set concrete tasks such as construction process, labor force management, etc.

\section{Legal Process of Planning}

Chinese lawyers have two approaches to back up reforming procedure legally.

- The first approach, they can make up laws which they need on the basis of strategic plan which can be made from Programs of Economic and Social development. For example, if we take the tenth Fife-Year Plan of economic and social development (2001-2005), one of the goal was to implement a Five-Year employment scheme in which it was necessary to provide agricultural sphere with labor resources. According to this, they had to reach $40 \mathrm{ml}$ employment level in agriculture and maintain urban employment level at more than 5\% intentionally. Certainly, a new law about employment appeared. One more goal of this program was to encourage development of SMEs. To realize this goal in 2002, a special law was created. It was called "Small and medium-sized enterprises stimulation" (16). This is how the first approach works.

- The second approach to law making process can be formulated as a creation of sub-laws for separate branches. Basing on economic and social plans, lawyers study which laws are needed for this or that sector. In comparison to the first approach, the second one allows to avoid some laws which are not needed for this or that branch. It is like a tailor-made law making process. Sub-laws are created as experimental ones. If such laws give positive effect then government can make a law for the whole country (Ian Yuntsyu, 2010). Today, if we look at the system of laws in the PRC we can see that Chinese lawyers need to summarize the whole legal procedure while they are preparing some laws.

\section{Mechanism of Law Making Process in Different Types of Programs}

It has following options:

- "From up to down";

- "From down to up";

- "Combination of these both options".

If we say about long term and middle term plans we have the following procedure:

First of all, the government creates recommendations about figures and results that they would like to see and send these numbers to all regions. Regions work on these recommendations and prepare drafts and after this they send these recommendations back to the government. The government improves such plans, and taking into consideration all aspects prepare the final program of economy and social development.

Five stages of law making process in different types of programs.

- The first stage is to create programs for economy development. The government considers a macroeconomic model and the strategy for development focusing on certain regions. These regions must be developed more than any others.

- The second stage is to create development plans for all regions taking into account main objects of the country. Such plans are created by institutions and province administration. All of those parties, taking into account prognoses of economic and social development plans with supply and de- mand market laws, create these plans. They do this in a form of consulting meetings taking into account all opinions of interesting parties and shareholders. After such meetings, as a result, they get a project plan. This project plan is usually given back to the government for confirmation.

- The third stage of law making process is based on planning by branches. This plan is closely connected with previously discussed stages. Here government institutions create programs of development for different branches taking into account demand and supply in this sector. When they have a project of planning in branches, sectoral institutions check these programs in forms of all aspects and after conformation they approve them as documents.

- The fourth stage is connected with regional program development. Regional institutions prepare project of regional plan which must be in connection with government program of economic development. It can be explained with the fact that all these planning programs have their own influence on strategic development program. This project of regional program must be discussed and adopted on a meeting of local level and after this it goes up to the government institutions.

- The fifth stage is correction in all types of programs. Initially, strategic development plans give general figures but after it goes to regional or sublevels, number and figures are checked and adopted. After this moment these figures can not be changed at all. All such corrections have regulatory nature (Kuzyk, 2008).

\section{Conclusion}

Having analyzed, this information we can make following conclusion.

Firstly, planning is actual and essential for economic growth.

Secondly, it is one of the main regulatory functions of government, which we can analyze in Chinese economy. With legal instruments, the PRC made effectively functioning economy.

Thirdly, accumulated experience shows that mechanism that was formulated in Chinese legal system could mitigate negative results of crisis. This mechanism proved to be vital in creation of market economy with strong government influence and it helped the PRC to survive in the world crisis. With the help of planning system it is possible to stimulate the world economy use different resources effectively and rationally.

Fourthly, Chinese model showed that it is possible to combine market mechanisms with government regulation of economy. That is why, in the PRC we can see multisided economy where private Foreign Direct Investment (FDI) and government sectors functioned together.

Fifth, in creating a market economy the PRC has not destroyed their planning system. They showed a specific model where we could connect planning and market relationship. It is possible to come from command methods of regulation economy to market, from directive to indirective. Chinese model demonstrated that liberalization in contrast with shock therapy moves to its aim gradually.

More than that, Chinese lawyers and economists proved that socialism can function together with market. Social economy mechanism can be based on planning and market systems. They do not contradict each other. With corresponding legal basis, 


\section{O. KUCHER}

planning works on macro-level and market system on microlevel, but in Chinese model they have influence on each other.

Chinese reforms turned out to be successful because society of Chinese people are not consuming but they have strict principles of consumption basing on Confucianism's principles. These principles say that motherland is more important for them than own success and wealth. The most surprising feature of this process is combination of traditions and modernization.

These days it is very important to use this mechanism of harmonization during reforms in order to combine planning system with innovations and new technologies. That is why, strategic planning has the main role in strategic development.

This concept of planning because of long term, middle term and short term plans with exact goals and real figures makes effective model. Chinese government institutions can easily change some mechanism in planning system because this system is flexible. And this fact allows to connect the whole system with some changes in the world and in the country.

Today, planning is not a centralized directive plan with figures which need to be done, but it is like one of the element of government regulation which allows to reach developed economy. Strategic planning gives opportunity to have milestones to develop countries or see the way how to develop country and presuppose factors which could influence other countries. That gives maximum competitive advantages to international economy.

\section{REFERENCES}

Atamanchuk, G. (2000). Governance (organizational-functional issues). Moscow.

\author{
Abbreviation \\ PRC: People's Republic of China \\ USA: United States of America \\ USSR: Union of Soviet Socialist Republics \\ UNO: United Nations Organization \\ SMEs: Small and Medium-sized Enterprises \\ FDI: Foreign Direct Investment
}

Kuzyk, B. (2008). Forecasting, strategic planning and national programming. Moscow: Economika.

Lortikyan, E. (1995). The historical experience and our reforms. Business-Inform, 45-46, 4-9.

Mamutov, V. (1982). Improving the legal regulation of economic activity. Kyiv: The Naukova Dumka.

Mikheev, V. (2000). Evolution of socio-economic model of China. Society and Economy, 3-4, 148-189.

Pakhomov, Y., \& Pavlenko, Y. (2008). Civilization of the east in the conditions of globalization (pp. 74-555). Kyiv: The Naukova Dumka.

Pawlowski, M. (1997). Chinese experience-lessons for Ukraine. Golos of Ukraine, February 25, 8-9.

Popova, E. (2008). Indicative planning is the main method of long-term socio-economic strategy of Russia. Innovations, 9, 15-27.

Selishchev, A., \& Selishchev, N. (2004). Chinese economy in the XXI century. St. Petersburg: The Peter.

Shen, L. C., \& Kazarinova, O. (2002). Economic reforms in China. Moscow: The Delo.

Shvetsov, A. (2009). Systematics of strategic planning tools of territorial development: An urgent needs and concrete suggestions. Russian Economic Journal, 5, 12-17.

Sukharev, O. (2001). Institutional reforms in the twentieth century. An evolutionary perspective on economic policy. Investment in Russia, 5 , 22-31.

The Law of the People's Republic (2011). On stimulation of small and medium enterprises. UGL Corporation (China). PRC laws, legislation and law in China. http://law.uglc.ru/stimulation.htm

Tszichun, S. (2007). On the mechanisms of planning management according to law. Economic Law, 7, 51.

Tymoshchuk, M. (2005). Indicative planning: International experience and prospects of its application in Ukraine. Regional Economics, 3, 230-236.

Yuntsyu, I., \& Shuang, F. (2010). Economic planning in China in terms of law. The doctrine of the right of control, 3, 12-20. 